\title{
JOGOS NA ALFABETIZAÇÃO MATEMÁTICA PARA ESTUDANTES COM DEFICIÊNCIA VISUAL NUMA PERSPECTIVA INCLUSIVA
}

\author{
JUEGOS EN LA ALFABETIZACIÓN MATEMÁTICA PARA ESTUDIANTES CON \\ DEFICIENCIA VISUAL EN UNA PERSPECTIVA INCLUSIVA
}

\author{
GAMES IN MATHEMATICAL LITERACY FOR STUDENTS WITH VISUAL \\ IMPAIRMENT IN NA INCLUSIVE PERSPECTIVE
}

\author{
Lúcia Virginia MAMCASZ-VIGINHESKI ${ }^{1}$ \\ Sani de Carvalho RUTZ DA SILVA ${ }^{2}$ \\ Elsa Midori SHIMAZAKI ${ }^{3}$ \\ Nilcéia Aparecida Maciel PINHEIRO ${ }^{4}$
}

RESUMO: A alfabetização matemática para estudantes com deficiência visual é um desafio ao professor do ensino regular, uma vez que a alfabetização desse estudante acontece juntamente com a alfabetização dos estudantes sem deficiência. Preocupados em auxiliar o professor do ensino regular nesta tarefa, este artigo apresenta algumas reflexões acerca do uso de jogos em sala de aula, como um recurso metodológico para a alfabetização matemática, assim como apresenta alguns jogos que podem ser adaptados para o ensino da disciplina de matemática para estudantes com deficiência visual. O trabalho foi desenvolvido a partir de pesquisa bibliográfica e da experiência profissional em uma Sala de Recursos Multifuncional do Tipo II, a qual presta atendimento especializado para estudantes com deficiência visual. Verificou-se que, utilizados de forma adequada, os jogos contribuem para o processo de ensino e aprendizagem de Matemática para estudantes com essa deficiência, se considerados alguns cuidados necessários na sua utilização.

PALAVRAS-CHAVE: Alfabetização matemática. Jogos. Inclusão. Deficiência visual.

RESUMEN: La alfabetización matemática para estudiantes con deficiencia visual es un reto al profesor de enseñanza regular, una vez que la alfabetización de ese estudiante ocurre juntamente con la alfabetización de los estudiantes sin deficiencia. Preocupados por auxiliar el profesor de enseñanza regular en esta tarea, este artículo presenta algunas reflexiones sobre el uso de juegos en sala de clase, como un recurso metodológico para la alfabetización matemática, así como presenta algunos juegos que pueden ser adaptados para la enseñanza

${ }^{1}$ Faculdade Guairacá, Guarapuava, PR - Brasil. Docente do Colegiado de Matemática. Docente da Associação de Pais e Amigos dos Deficientes Visuais, Guarapuava, Paraná. ORCID: <https://orcid.org/0000-0002-64740927>. E-mail: 1mamcaszviginheski@gmail.com

2 Universidade Tecnológica Federal do Paraná (UTFPR), Ponta Grossa - PR - Brasil. Docente do Programa de Pós-Graduação em Ensino de Ciência e Tecnologia - (PPGECT). ORCID: <https://orcid.org/0000-0002-15485739>.E-mail: sani@utfpr.edu.br

3 Universidade Estadual de Maringá (UEM), Maringá - PR - Brasil. Docente do Programa de Pós-Graduação em Educação - (PPGE). ORCID: <https://orcid.org/0000-0002-2225-5667>. E-mail: emshimazaki@uem.br 4 Universidade Tecnológica Federal do Paraná - (UTFPR), Ponta Grossa - PR - Brasil. Docente do Programa de Pós-Graduação em Ensino de Ciência e Tecnologia (PPGECT). ORCID: <https://orcid.org/0000-0003-33131472>.E-mail: nilceia@utfpr.edu.br

RIAEE - Revista Ibero-Americana de Estudos em Educação, Araraquara, v. 14, n. 2, p. 404-419, abr./jun. 2019. E-ISSN: 1982-5587. DOI: $10.21723 /$ riaee.v14i2.8893 
de la asignatura de matemáticas para estudiantes con deficiencia visual. El trabajo fue desarrollado a partir de investigación bibliográfica y de la experiencia profesional en una Sala de Recursos Multifuncional en el área de deficiencia visual. Se averiguó que, utilizados de forma adecuada, los juegos contribuyen para el proceso de enseñanza y aprendizaje de Matemáticas para estudiantes con esa deficiencia, si considerados algunos cuidados necesarios en su utilización.

PALABRAS CLAVE: Alfabetización matemática. Juegos. Inclusión. Deficiencia visual.

ABSTRACT: Mathematical literacy for students with visual impairments is a challenge to the teacher's regular education, since literacy that student happens with literacy students without disabilities. Anxious to help the teacher regular education is this task, this article presents some reflections on the use of classroom games, as a methodological resource for mathematical literacy, as well as presents some games which can be adapted to the mathematical discipline for students with visual impairment. The work was developed from bibliographic research and professional experience in a Multifunctional Resource Room Type II, which provides specialized care for students with visual impairment. Checked that, used appropriately, the games contribute to the process of teaching and learning mathematics for students with disabilities that, are considered some necessary care in its use.

KEYWORDS: Literacy mathematics. Games. Inclusion. Visual impairment.

\section{Introdução}

A inclusão de estudantes com deficiência visual nas escolas e a preocupação com a qualidade do ensino de Matemática têm levado muitos professores a buscarem diferentes formas de trabalho pedagógico que promovam a alfabetização matemática desses estudantes para garantir-lhes o acesso e a apropriação dos conteúdos dessa disciplina, bem como fazer uso deles nas diferentes áreas do conhecimento e em suas práticas sociais.

Desde o início do século passado existem registros de matrículas de estudantes com deficiência visual nas escolas regulares (ARANHA, 2000). Entretanto, enquanto a Educação Especial se configurava como um sistema de ensino paralelo ao ensino regular, era comum educação escolar desses estudantes em instituições especializadas antes de serem matriculados no ensino regular. Com o advento da inclusão, movimento que ganhou forças a partir da década de 1990, a Educação Especial foi reestruturada no sentido de, em conjunto com o ensino regular, estabelecer medidas que garantam o acesso e a permanência dos estudantes com deficiência. Com isso, os estudantes com deficiência visual passaram a ser alfabetizados junto com as crianças das turmas nas quais estavam matriculados, recebendo da 
Educação Especial serviços de apoio complementares à educação básica, quando necessário, como estabelece a Resolução 04/2009 do Ministério da Educação ${ }^{5}$.

A realidade do cenário das escolas mostra que apesar da legislação anteriormente citada e outras, o número de estudantes ainda é elevado nas turmas dos anos iniciais do ensino fundamental, os materiais adaptados e diversificados não são suficientes para atender a demanda, as condições ainda são precárias. É, de certo modo, um desafio ao professor alfabetizar os estudantes com deficiência visual juntamente com os demais, tanto no que diz respeito à alfabetização da língua materna, como da Matemática.

A autora Danyluk (2002, p. 20) define a alfabetização matemática como "fenômeno que trata da compreensão, da interpretação e da comunicação, de conteúdos matemáticos ensinados na escola, tido como iniciais para a construção do conhecimento matemático".

Para Santos (2015, p. 30), a relação existente entre a alfabetização e a alfabetização matemática diz respeito ao fato de que as habilidades de comunicação como o falar, escutar, ler, escrever e representar se constituem como habilidades para a aprendizagem da Matemática, ao mesmo tempo que promovem a interdisciplinaridade entre as diferentes áreas do conhecimento. Para a autora, "no processo de alfabetização das crianças, a Matemática é uma aliada que coopera no processo de comunicação e no desenvolvimento de múltiplas linguagens".

Dessa forma, compreendemos que a alfabetização matemática envolve as ações ler, escrever e interpretar o que se leu e se escreveu, ações estas que estabelecem a relação existente entre a alfabetização na língua materna e a alfabetização matemática.

Ao conceberem a alfabetização como leitura, escrita e interpretação, e a necessidade do uso dessas ações nas diferentes práticas sociais, Galvão e Nacarato (2013) consideram o letramento como o processo em que ocorre a aquisição do código de registro escrito da língua, caracterizando a leitura e a escrita como práticas sociais. Elas apontam que: "[...] diante da demanda exigida ao indivíduo pela sociedade contemporânea, ser alfabetizado significa saber ler, escrever, interpretar textos e possuir habilidades matemáticas que o façam agir criticamente na sociedade" (GALVÃO; NACARATO, 2013, P. 83).

Entre as práticas sociais vivenciadas pelas crianças em fase de a alfabetização, sejam elas crianças com deficiência visual ou não, destacam-se os jogos e as brincadeiras. Dessa forma, ao se pensar o ensino de Matemática nos anos iniciais numa perspectiva de alfabetização matemática, promovendo aos estudantes com deficiência visual as mesmas

${ }^{5}$ Disponível em: www.abiee.org.br. Acesso em 26 ago. 2016

RIAEE - Revista Ibero-Americana de Estudos em Educação, Araraquara, v. 14, n. 2, p. 404-419, abr./jun. 2019. E-ISSN: 1982-5587. DOI: $10.21723 /$ riaee.v14i2.8893 
oportunidades de aprendizagem em conjunto com os demais estudantes, partimos do seguinte questionamento para o desenvolvimento deste artigo: como e quais jogos podem ser utilizados pelos professores do ensino regular para promover a alfabetização matemática dos estudantes com deficiência visual inclusos no ensino regular?

Diante disso, o objetivo principal deste artigo é apresentar as contribuições do uso de jogos como encaminhamento metodológico para o ensino de Matemática para estudantes com deficiência visual inclusos no ensino regular.

Utilizamos como metodologia de pesquisa a pesquisa bibliográfica e a pesquisa exploratória, por meio do levantamento de jogos adaptados para a alfabetização matemática para estudantes com deficiência visual em uma Sala de Recursos Multifuncional do Tipo II em uma escola municipal do interior do estado do Paraná.

\section{Alfabetização matemática para estudantes com deficiência visual}

O documento Saberes e Práticas da Inclusão (BRASIL, 2006) considera que, para o ensino da Matemática para estudantes com deficiência visual, sejam eles cegos ou com baixa visão, deve-se considerar que estes apresentam as mesmas condições que os alunos sem limitações visuais para o aprendizado dessa disciplina, observadas as adaptações necessárias quanto às representações gráficas e aos recursos didáticos. Também aponta para a necessidade de o professor buscar informações sobre os materiais disponíveis para o ensino da Matemática para pessoas com deficiência visual, como livros didáticos adaptados em Braille, o domínio que o aluno apresenta com relação ao código Braille, ao uso do soroban e ao cálculo mental, a disponibilidade de recursos pedagógicos adaptados.

Por muito tempo, o ensino de Matemática para as pessoas cegas resumia-se basicamente ao uso do soroban ${ }^{6}$, como instrumento de cálculo, e ao código braille ${ }^{7}$, para o registro das operações realizadas. A utilização limitada desses recursos, os estudantes com deficiência visual eram alfabetizados em Matemática de forma mecânica, apresentando com isso muitas dificuldades na elaboração de seus conteúdos.

Fernandes et al. (2006) aponta que noções e representações matemáticas se fazem presentes não somente nas atividades estruturadas da escola, mas também nas brincadeiras das crianças, sendo estas, para Piaget, a primeira possibilidade de pensamento propriamente dito. Como a criança com deficiência visual se relaciona dinamicamente com o mundo, os jogos

${ }^{6}$ Instrumento de cálculo japonês, adaptado pelo brasileiro Joaquim Morais para uso pelos cegos.

${ }^{7}$ Sistema de escrita e leitura tátil, desenvolvido por Louis Braille. 
também podem ser adequados à compreensão e formação do pensamento simbólico, importante para consolidar os rudimentos do pensamento lógico-matemático.

Amiralian apud Fernandes et al. (2006), considera a formação de conceitos, a classificação, o raciocínio, as representações mentais e outras funções cognitivas fatores críticos para o ensino de crianças com deficiência visual. Estas dependem da mediação de outra pessoa para o seu desenvolvimento, da utilização de objetos táteis e métodos apropriados para a experimentação e obtenção das informações táteis, e flexibilidade curricular.

Consideramos essas questões importantes para a alfabetização matemática para as crianças com deficiência visual, fazendo-se necessário a criação de um ambiente adequado para que possamos oportunizar lhes a apropriação do conhecimento científico que foi desenvolvido no decorrer da história, da qual elas também fazem parte.

A falta de visão exige da pessoa a utilização de outros canais, como, por exemplo, o tato, para o acesso ao conhecimento e à informação. Assim, conceitos matemáticos podem ser desenvolvidos por meio da utilização de materiais táteis, manipuláveis, que podem oferecer a estes alunos condições necessárias para a construção dos conhecimentos. Entre esses materiais podemos incluir os jogos.

Culturalmente, muitas crianças com deficiência visual não têm acesso aos jogos que outras normalmente têm, pelo fato de que, muitas pessoas, pensam que a falta de visão os limita para essa e outras atividades. No entanto, os jogos proporcionam às pessoas com deficiência visual as mesmas vantagens consideradas para as pessoas sem limitação visual, se levados em consideração alguns cuidados.

Ao optar pela utilização dos jogos em sala de aula, o professor primeiramente precisa avaliar a adequação do material para o aluno com deficiência visual; que adaptações se fazem necessárias; e se os objetivos a serem atingidos podem ser os mesmos com relação aos demais aprendizes e outras observações pertinentes ao seu uso.

\section{Os jogos na alfabetização matemática}

Os Parâmetros Curriculares Nacionais de Matemática - PCN (BRASIL, 1998), apontam diferentes caminhos para que o ensino da disciplina aconteça de forma contextualizada, significativa e considerando os conhecimentos prévios dos alunos, articulando seus conteúdos de maneira que eles não sejam desenvolvidos de forma fragmentada, seguindo a ideia de linearidade entre eles, mas sim, elaborados pelos alunos a 
partir de diferentes situações. A história da matemática, as tecnologias da comunicação, e os jogos são alguns dos recursos apresentados.

Com relação aos jogos, os PCN (BRASIL, 1998, p. 46) consideram-nos como:

uma forma interessante de propor problemas, pois permitem que estes sejam apresentados de modo atrativo e favorecem a criatividade na elaboração de estratégias de resolução e busca de soluções. Propiciam a simulação de situações problema que exigem soluções vivas e imediatas, o que estimula o planejamento das ações; possibilitam a construção de uma atitude positiva perante os erros, uma vez que as situações sucedem-se rapidamente e podem ser corrigidas de forma natural, no decorrer da ação, sem deixar marcas negativas.

Dessa forma, podemos perceber ser grande a contribuição dessa metodologia em sala de aula, por meio da qual, muitos problemas relacionados com a dificuldade de aprendizagem da disciplina e desenvolvimento do pensamento lógico podem ser amenizados e até mesmo solucionados.

Ainda segundo o documento, o jogo pode ser considerado como um instrumento que contribui para o exercício da argumentação e a organização do pensamento, formação de atitudes, necessárias para a aprendizagem da Matemática.

Entre tantas, uma das principais funções do jogo como instrumento metodológico é contribuir para o desenvolvimento de conceitos matemáticos de forma lúdica. Fazer uso dele como encaminhamento metodológico permite ao professor promover a articulação entre os conteúdos, criar situações problemas a partir deles, levar o estudante a pensar independentemente, contribuindo para o desenvolvimento do pensamento lógico-matemático. Por meio de atividades envolvendo jogos, Mendes (2009) considera haver uma estrutura matemática que vai sendo redescoberta por meio da ação do aluno. Emerique (1999) considera as atividades lúdicas alternativas eficientes para motivar o ensino não só da matemática, como também diferentes conteúdos de diferentes disciplinas.

Para Vygotski (1998) o desenvolvimento da criança se dá por diferentes níveis. O primeiro nível diz respeito ao que a criança consegue realizar sozinha, denominado por nível de desenvolvimento real. O segundo nível, denominado por nível de desenvolvimento proximal se caracteriza por aquilo que a criança conseguirá resolver com independência, após a mediação entre ela e o professor e/ou seus colegas. A etapa denominada por zona de desenvolvimento proximal é o intervalo entre os conhecimentos que já estão consolidados e os conhecimentos que estão em fase de maturação. 
Segundo Vygotski (1998, p. 113) quando o professor, em sua prática de ensino, cria zonas de desenvolvimento proximal, ou seja, oferece à criança atividades desafiadoras, que vão além do que ela consegue fazer sozinha, estimula vários processos internos de desenvolvimento resultando em desenvolvimento mental. Para o autor, "a noção de zona de desenvolvimento proximal hoje, será o nível de desenvolvimento real amanhã, ou seja, aquilo que a criança pode fazer com assistência hoje, ela será capaz de fazer sozinha amanhã”.

Para este teórico (VYGOTSKI, 1998), os jogos e o brinquedo têm uma função muito importante no desenvolvimento da criança. Por mais simples que seja um jogo, o fato de ser regulamentado por regras, as possibilidades de ações são pré-determinadas, transformando-se de situação real em situação imaginária. Assim, a criança aprende a agir não apenas incentivada pelos objetos externos, mas também dentro de uma esfera cognitiva interna, pelo seu significado.

A criança consegue elaborar conceitos funcionais sobre as coisas por meio dos jogos ou dos brinquedos e por meio de palavras a eles relacionadas. Em função disso, o jogo e o brinquedo contribuem para o desenvolvimento de zonas de desenvolvimento proximal. Para Vygotski (1998, p. 69):

Assim, o brinquedo cria uma zona de desenvolvimento proximal da criança. No brinquedo, a criança sempre se comporta além do comportamento habitual de sua idade, além de seu comportamento diário; no brinquedo é como se ela fosse maior do que é na realidade. Como no foco de uma lente de aumento, o brinquedo contém todas as tendências do desenvolvimento sob forma condensada, sendo, ele mesmo, uma grande fonte de desenvolvimento.

Além de conceitos que podem ser desencadeados pela utilização de jogos para o ensino da Matemática, encontramos contribuições em outras áreas. Batllori (2006) enumera algumas capacidades, conhecimentos, atitudes e habilidades desenvolvidas por meio dos jogos. São elas: estimula a comunicação; ajuda a desenvolver a imaginação; facilita a aquisição de novos conhecimentos; desenvolve a lógica e o sentido comum; proporciona experiências; ajuda a explorar potencialidades e limitações; incentiva a confiança; estabelece e revisa valores; ajuda na abordagem de temas transversais ao currículo; apressura o raciocínio verbal, numérico, visual e abstrato; entre outras.

Com relação à revisão de valores, Emerique (1999) considera importante o fato de o jogo abordar a relação ganhar/perder, sendo esta estendida e em diversas situações do cotidiano, nas quais nem sempre ganhamos. Essa questão pode levar o aluno a uma reflexão crítica sobre a proposta capitalista de ganhar sempre. 
Concordamos com Grando (1997) ao considerar que o jogo se apresenta produtivo tanto ao professor, quanto ao aluno. Com relação ao professor, por utilizar o jogo como um instrumento facilitador da aprendizagem do aluno e, ao aluno, por permiti-lo desenvolver sua capacidade para pensar, refletir, analisar, levantar hipóteses, testando-as e avaliando-as, construindo seus conhecimentos com autonomia e cooperação com seus colegas.

Enfim, o jogo configura-se como um excelente aliado ao ensino não só da Matemática, como de outras disciplinas, proporcionando, a todos os estudantes, condições de serem os protagonistas na apropriação do conhecimento, contextualizado, significativo.

\section{Alguns jogos que podem ser utilizados na alfabetização matemática dos estudantes com deficiência visual}

As diretrizes nacionais para o ensino de Matemática nos anos iniciais do Ensino Fundamental (BRASIL, 1998) orientam que os conhecimentos numéricos, geométricos, métricos, ente outros, sejam abordados de forma articulada entre si, uma vez que favorecem aos estudantes a apropriação dos significados estabelecendo relações entre eles. Diante disso, apresentamos alguns jogos e materiais adaptados para estudantes com deficiência visual que podem ser utilizados em sala de aula para a elaboração do conceito de número natural, do Sistema de Numeração Decimal e das operações com quantidades, associadas a outros conteúdos como Geometria, Grandezas e Medidas e Tratamento da Informação. Entre eles, os Blocos Lógicos e outras adaptações a partir dele, o Quebra Cabeça das Quatro Cores, o Jogo dos Critérios, Jogo 50 Fichas e Jogos de Agrupamento.

\section{Blocos Lógicos}

Mendes (2009) relata que o educador canadense Zoltan Paul Dienes desenvolveu pesquisas em vários lugares do mundo, buscando desenvolver o raciocínio lógico matemático sob a luz da teoria de Jean Piaget. A partir de seus trabalhos, os blocos lógicos passaram a ser utilizados como jogo.

O material é constituído por 48 blocos, apresentados por meio de quatro atributos: cor (vermelho, amarelo e azul), forma (quadrado, triângulo, círculo e retângulo), tamanho (grande e pequeno) e espessura (grosso e fino). Todas as peças apresentam características semelhantes entre si, porém, nenhuma é igual à outra.

Por meio deste material é possível abordar a classificação, a seriação, o pensamento lógico, união, intersecção, inclusão e exclusão de classes, entre outros conceitos necessários 
para a elaboração do conceito de número. Em seu livro, a autora propõe 150 jogos e atividades que podem ser desenvolvidos com o uso do material, além de apontar observações e intervenções necessárias durante o desenvolvimento das atividades pelas crianças.

Como estamos considerando a proposta de jogos na alfabetização matemática para estudantes com deficiência visual inclusos no ensino regular, ao utilizar os blocos lógicos, as pessoas cegas não conseguirão identificar o atributo cor, por se tratar de uma característica visual. Nesse caso, sugerimos a adaptação do material substituindo a cor por textura. Realizada essa adaptação, o material poderá ser utilizado simultaneamente com todos os alunos, com ou sem limitação visual, contribuindo para a inclusão dessas pessoas nas atividades pedagógicas. A Figura 1 retrata o material adaptado com texturas pelas professoras especialistas da Sala de Recursos Multifuncional do Tipo II de uma escola do município de Guarapuava, Paraná:

Figura 1: Blocos Lógicos Adaptados

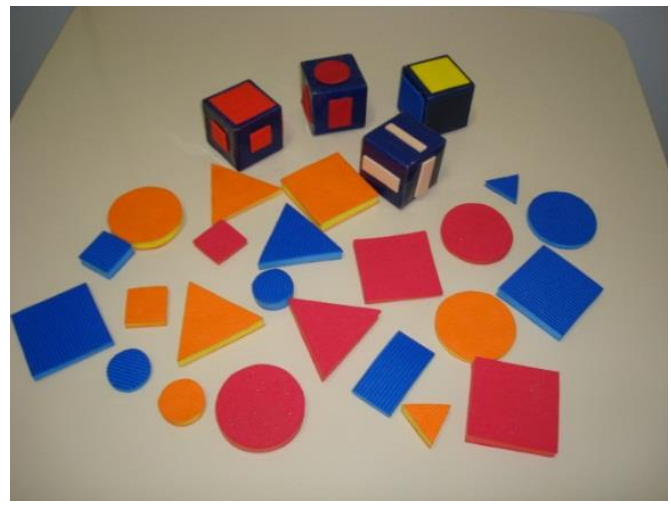

Fonte: Acervo da pesquisadora

Outra observação pertinente refere-se ao fato de que não basta utilizar o material uma única vez na sala de aula e seu constante uso pode causar desinteresse no aprendiz, tornandose então um material desmotivador. Para que possamos explorar ao máximo todas as contribuições que os materiais trazem, faz-se necessário explorá-los em muitos momentos e para que não se torne maçante, cansativo, o professor pode lançar mão de sua criatividade e realizar outras adaptações, e até mesmo criar novos materiais.

Com relação a isso, apresentamos na Figura 2 outros materiais que podem ser utilizados para a diversificação das atividades. O material denominado por Almofadinhas Lógicas, o qual foi idealizado por uma das professoras da sala de recursos, tendo como base para a sua construção os Blocos Lógicos. Foram considerados os seguintes atributos: textura (foram utilizados seis tipos diferentes de tecido); presença ou ausência de franjas; tamanho 
(pequeno, médio e grande) e botões ( 0,1 e 2 botões). Combinando os atributos 6 texturas x 2 franjas x 3 tamanhos x 3 botões obtemos um total de 108 almofadas.

Figura 2: Almofadinhas Lógicas

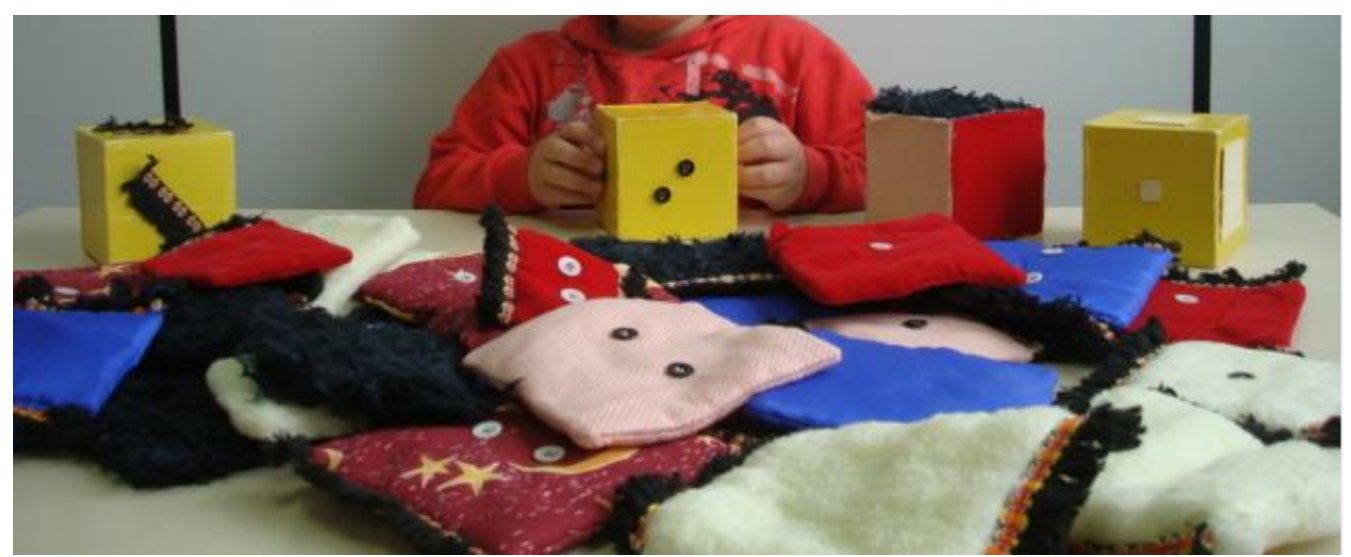

Fonte: Acervo da pesquisadora

A Figura 3 apresenta outras adaptações de materiais a partir dos Blocos Lógicos, os quais podem ser utilizados para trabalhar os mesmos conceitos que estes, por crianças que apresentam baixa visão:

Figura 3: Outras adaptações a partir dos Blocos Lógicos

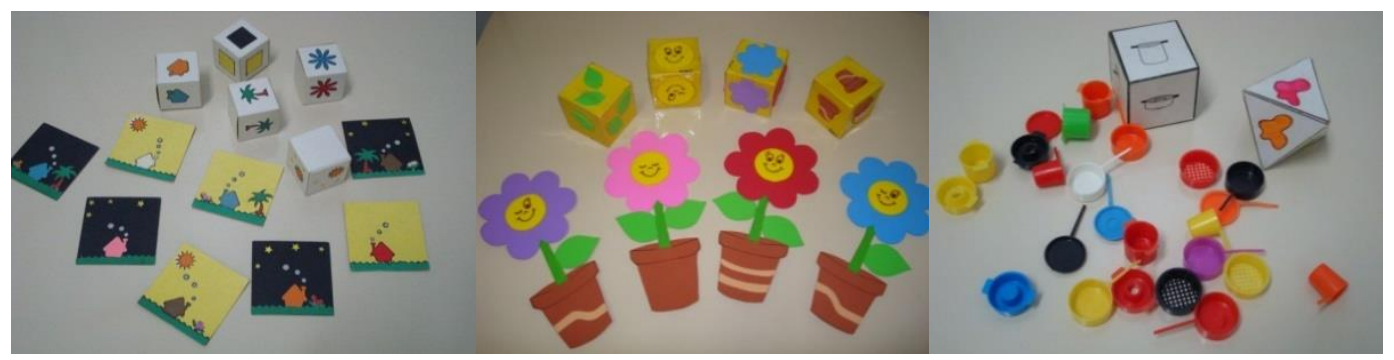

Fonte: Acervo da pesquisadora

A primeira imagem da Figura 3 refere-se ao jogo Cenários Lógicos, cujos atributos são: cores da casa, fundo (noite/dia), ausência/presença de astros, ausência/presença de flores, ausência/presença de palmeiras. A segunda imagem da Figura 3 retrata o jogo Florezinhas Lógicas, com os atributos: cor, expressão fisionômica, quantidade de folhas e detalhes nos vasos; e, por último, na terceira imagem da Figura 3, o jogo das Panelinhas, com os atributos cor e forma. Da mesma forma que os Blocos Lógicos e as Almofadinhas Lógicas, estes materiais podem ser utilizados por crianças com e sem deficiência visual para explorar conceitos que antecedem a elaboração do conceito de número. 


\section{Quebra Cabeça Quatro Cores}

Segundo Macedo (1997), o Jogo das Quatro Cores foi criado a partir de observações de Francis Guthrie sobre a pintura de mapas, na maioria, pintados com apenas quatro cores, respeitando-se o critério de não utilizar as mesmas cores em territórios adjacentes.

O quebra cabeça das Quatro Cores faz uso das mesmas regras utilizadas para a pintura de mapas: deve-se formar um quadrado de forma que cores iguais não sejam adjacentes, nem mesmo nos vértices. Pode ser jogado individualmente ou em duplas. Segundo Macedo (1997), ao propor o jogo em dupla, pode-se fazer uso de dois procedimentos: cada jogador, à sua vez, coloca uma peça, perdendo o jogo aquele que não conseguir encaixar uma peça na área do quadrado; ou então, cada jogador escolhe nove peças antes do início da partida e, intercalando, cada um coloca uma de suas peças até que não se possa colocar mais nenhuma. Nessa forma de jogar, ganha quem ficar com a menor quantidade de peças.

O Quebra cabeça das Quatro Cores foi adaptado para estudantes cegos fazendo uso de tecidos com diferentes texturas. Com eles é possível jogar com as mesmas regras estabelecidas. A Figura 4 representa a adaptação:

\section{Figura 4: Quebra Cabeça das Quatro Cores}

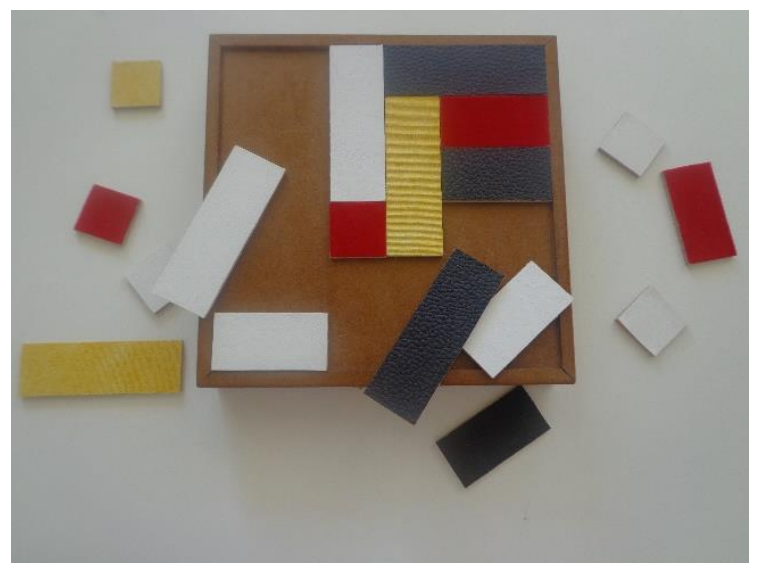

Fonte: Acervo da pesquisadora

Para Macedo (1997), o jogo Quatro Cores estimula a concentração, o domínio das relações espaço - temporais, no sentido de planejar e antecipar as ações, operar com a negação e a afirmação, de acordo com as restrições impostas pelas regras, desenvolver estratégias, entre outras coisas. Assim, oportunizar aos estudantes com deficiência visual o acesso a esse jogo permite-lhes também o desenvolvimento dessas habilidades. 


\section{Jogo dos Critérios}

O jogo dos critérios, de origem desconhecida, constitui-se de um tabuleiro formado por seis linhas e seis colunas, por fichas com diferentes formas e texturas e por três dados, um para o sorteio da quantidade, outro para o sorteio da textura e outro para o sorteio da forma. A adaptação para os estudantes cegos foi realizada pela utilização de relevo para dividir o tabuleiro em linhas e colunas e pelas fichas confeccionadas em EVA com textura. Por meio do jogo é possível estimular a habilidade tátil, desenvolver conceitos como quantidade, classificação, seriação, organização espacial, além de desenvolver funções psicológicas como atenção, percepção, pensamento, entre outras.

Para o jogo, o jogador da vez lança os dados da textura, da quantidade e da forma, simultaneamente e faz o registro em sua cartela. A pontuação pode ser pelo preenchimento de figuras ou cores iguais na mesma linha ou coluna. Outras regras podem ser estabelecidas entre os jogadores. Para desmontar a cartela, pode ser utilizado apenas o dado da quantidade. A Figura 5 representa o jogo adaptado para estudantes com deficiência visual:

Figura 5: Jogo dos Critérios

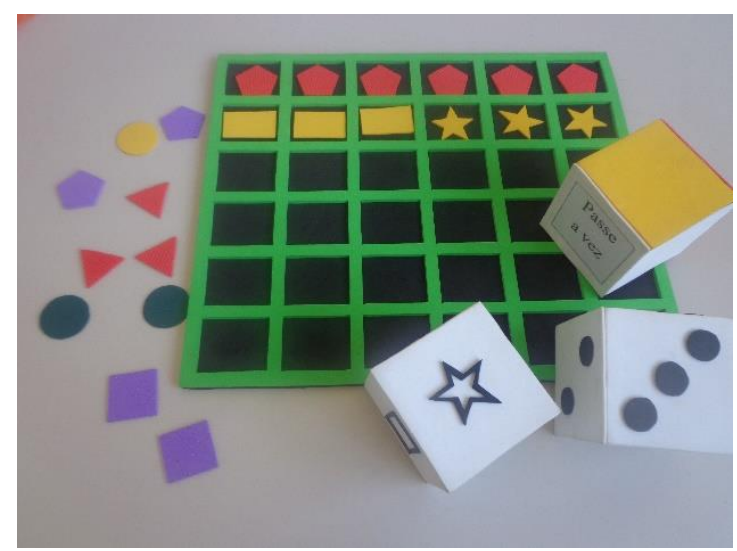

Fonte: Acervo da pesquisadora

\section{Jogo 50 Fichas}

Este jogo é uma adaptação do jogo proposto por Kamii e Declark (1991). O jogo é constituído por uma tabela quadriculada para cada jogador, com cores ou texturas diferentes, formada por cinco linhas e dez colunas; um dado cujas faces tem as cores ou texturas das tabelas, um dado com quantidades e cinquenta fichas quadradas nas cores ou texturas de cada uma das tabelas. O jogador da vez lança os dois dados simultaneamente, sorteando a quantidade de fichas a serem colocadas na tabela de cor ou textura correspondente à face 
sorteada pelo dado. Vence o jogador que primeiro preencher sua tabela. Este jogo pode ser utilizado para contagem, comparação de quantidades, construção do número. A Figura 6 representa o jogo, adaptado para estudantes cegos da mesma forma que o Jogo dos Critérios:

Figura 6: Jogo 50 Fichas

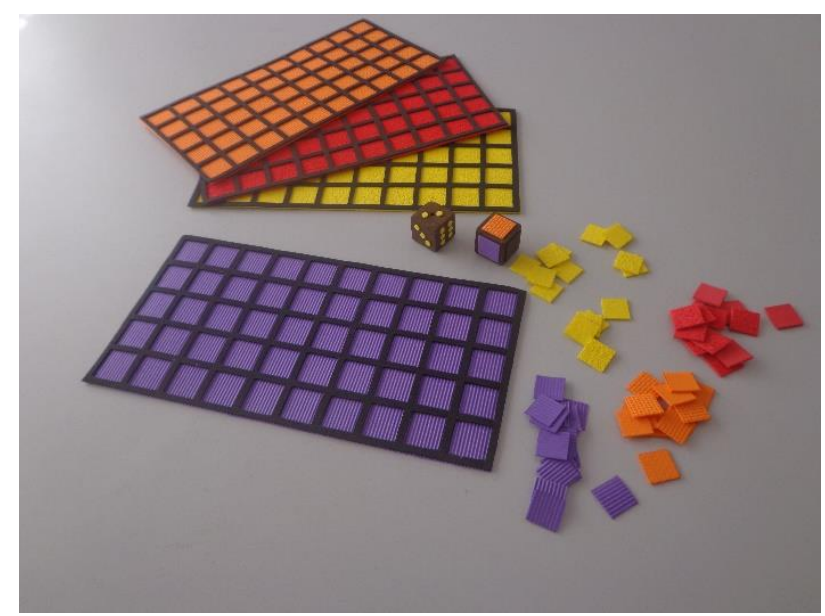

Fonte: Acervo da pesquisadora

\section{Jogos para quantificação e agrupamentos}

Estes jogos têm como objetivo a quantificação, os agrupamentos e a compreensão da lógica do sistema de numeração decimal ou de diferentes bases. O jogo do Nunca Solto pode ser jogado com diferentes materiais, estruturados ou não. Entre esses materiais, podemos citar o Material Dourado, utilizado exclusivamente para a estruturação da base dez. Este, em específico, é constituído por unidades cúbicas, barras com dez unidades cúbicas agrupadas, placas com cem unidades cúbicas agrupadas e um cubo com mil unidades cúbicas agrupadas.

Para o jogo do Nunca Dez Solto, o qual aborda a base decimal, o jogador da vez sorteia a quantidade de unidades cúbicas por meio de um dado. Ao conquistar dez unidades cúbicas, troca pela barra com dez unidades cúbicas agrupadas e, ao conquistar dez barras, troca-as por uma placa. $\mathrm{O}$ vencedor do jogo é o jogador que primeiro conquistar a placa. Outras bases podem ser trabalhadas da mesma forma, porém, com materiais diferentes. A Figura 7 apresenta alguns exemplos de materiais estruturados ou não estruturados, para o jogo do Nunca Solto em diferentes bases, os quais podem ser utilizados tanto pelos estudantes cegos como pelos estudantes que enxergam, sem a necessidade de alguma adaptação especial, uma vez que os atributos podem ser percebidos tatilmente: 
Figura 7: Materiais para jogo do Nunca Solto em diferentes bases

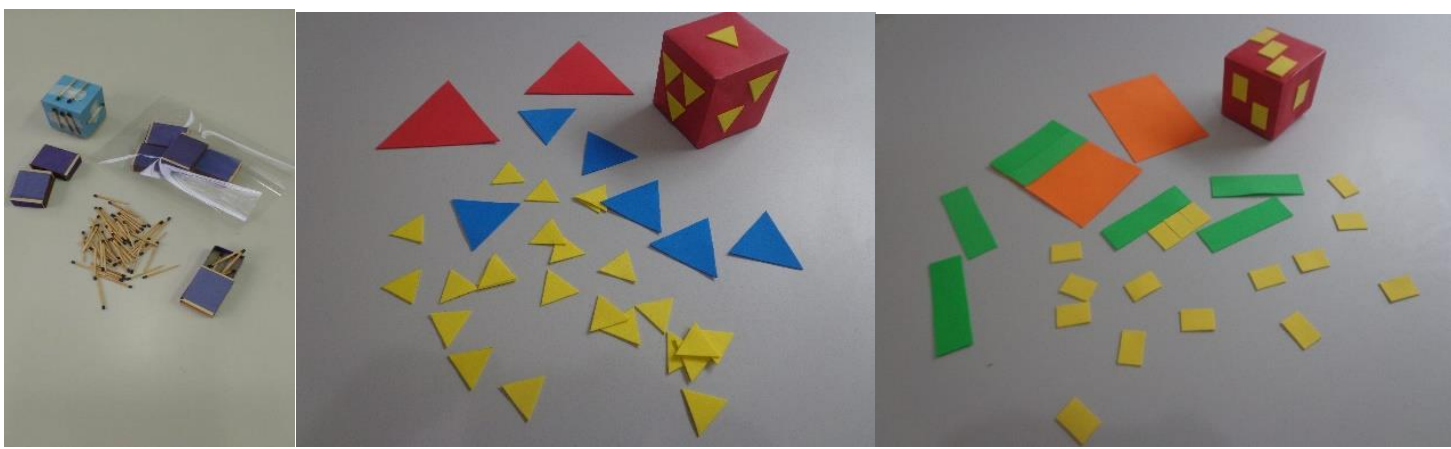

Fonte: Acervo da pesquisadora

\section{Considerações finais}

Por meio dessas reflexões, verificamos que os jogos, quando utilizados de forma adequada, contribui para processo de ensino e aprendizagem, porque trata-se de um instrumento mediador que proporciona condições para o aluno pensar, questionar, decidir, valorizar e, dessa forma, ajuda na elaboração do conhecimento e, consequentemente, à formação da cidadania. Da mesma forma, contribui para a inclusão dos estudantes com deficiência visual no processo de alfabetização, proporcionando-lhes as mesmas condições que os demais estudantes. Para tanto é necessário oferecer aos estudantes um ensino que realmente contribua para a sua formação, contextualizando-o, atendendo a suas necessidades.

Atribuímos ao professor a responsabilidade de planejar suas ações. É necessário a ele escolha com propriedade as atividades são necessárias para a efetivação dos objetivos que propõe e para tanto. É importante que conheça as necessidades de seus estudantes, a diversidade da sala, planejando aulas acessíveis, de forma que todos possam participar ativamente no processo de apropriação do conhecimento. Nesta diversidade, incluímos as pessoas com deficiência visual, que apresentam condições suficientes para serem alfabetizados tanto na língua materna quanto na Matemática juntamente aos demais estudantes. No entanto, necessita-se da sensibilidade do professor em possibilitar-lhes condições necessárias para que isso de fato aconteça.

\section{REFERÊNCIAS}

ARANHA, Maria Salete Fábio. Visão histórica. Projeto Escola Viva. Garantindo o acesso e a permanência de todos os alunos na escola. Alunos com necessidades educacionais especiais. Caderno 1. Brasília: MEC, SEESP, 2000. 
BRASIL. Ministério da Educação e Cultura. Parâmetros Curriculares Nacionais Matemática. Brasília: MEC, 1998.

BRASIL. Saberes e práticas da inclusão: desenvolvendo competências para o atendimento às necessidades educacionais especiais de alunos cegos e de alunos com baixa visão. [2. ed.] / coordenação geral SEESP/MEC. - Brasília: MEC, Secretaria de Educação Especial, 2006.

BATLLORI, Jorge. Jogos para treinar o cérebro: desenvolvimento de habilidades cognitivas e sociais. São Paulo: Madras, 2006.

DANYLUK, Ocsana. Alfabetização matemática: as primeiras manifestações da escrita infantil. Porto Alegre: Ediupf, 2002.

EMERIQUE, Paulo Sérgio. Isto e aquilo: jogo e “ensinagem” Matemática. In: BICUDO, Maria Aparecida Viggiani. (org.). Pesquisa em educação matemática: concepções e perspectivas. São Paulo: Editora UNESP, 1999.

FERNANDES, Cleonice Terezinha; et al. A construção do conceito do número e o présoroban. Brasília: Ministério da Educação, Secretaria de Educação Especial, 2006.

GALVÃO, Elizangela da Silva.; NACARATO, Adair Mendes. O letramento matemático e a resolução de problemas na provinha brasil. Revista Eletrônica de Educação, v. 7, n. 3, p. 8196, 2013.

GRANDO, Regina Célia. A construção do conceito matemático no jogo. Revista de Educação Matemática - ano 5, n. 3, 1997.

KAMII, Constance; DECLARK, Georgia. Reinventando a aritmética: Implicações da teoria de Piaget. Campinas: Papirus, 1991.

MACEDO, Lino de. Quatro cores, senha e dominó: oficinas de jogos em uma perspectiva construtivista e psicopedagógica. São Paulo: Casa do Psicólogo, 1997.

MENDES, Iran Abreu. Matemática e investigação em sala de aula: tecendo redes cognitivas na aprendizagem. São Paulo: Livraria da Física, 2009.

SANTOS, Francely Aparecida dos. A matemática como um texto. In: BRASIL. Pacto nacional pela educação na idade certa: alfabetização matemática na perspectiva do letramento. Caderno 07. Brasília: MEC, SEB, 2015.

SIMONS, Ursula Marianne. Blocos Lógicos: 150 exercícios para flexibilizar o raciocínio. Petrópolis: Vozes, 2007.

VYGOTSKI, Lev Semenovich. A formação social da mente. 6. ed. São Paulo: Martins Fontes, 1998. 


\section{Como referenciar este artigo}

SHIMAZAKI, E. M.; PINHEIRO, N. A. M.; RUTZ DA SILVA, S. de C.; MAMCASZVIGINHESKI, L. V. Jogos na alfabetização matemática para alunos com deficiência visual numa perspectiva inclusiva. Revista Ibero-Americana de Estudos em Educação, Araraquara, v. 14, n. 2, p. 404-419, abr./jun. 2019. E-ISSN: 1982-5587. DOI: 10.21723/riaee.v14i2.8893

Submetido em: 30/08/2016

Revisões requeridas: 20/07/2017

Aprovado em: 10/03/2018 